\title{
EphA4-Mediated Ipsilateral Corticospinal Tract Misprojections Are Necessary for Bilateral Voluntary Movements But Not Bilateral Stereotypic Locomotion
}

\author{
Najet Serradj, ${ }^{1}$ Sónia Paixão, ${ }^{2}$ Tomasz Sobocki, ${ }^{1}$ Mitchell Feinberg, ${ }^{1}$ Rüdiger Klein,,${ }^{2,3}$ Klas Kullander, ${ }^{4}$ \\ and John H. Martin ${ }^{1}$ \\ 'Department of Physiology, Pharmacology and Neuroscience, City College of the City University of New York, New York, New York 10031; ${ }^{2}$ Department of \\ Molecules-Signaling-Development, Max Planck Institute of Neurobiology, D-82152 Martinsried, Germany, ${ }^{3}$ Munich Cluster for Systems Neurology \\ (SyNergy), D-80336 Munich, Germany; and 4Department of Neuroscience, Science for Life Laboratory, University of Uppsala, 75124 Uppsala, Sweden
}

In this study, we took advantage of the reported role of EphA4 in determining the contralateral spinal projection of the corticospinal tract (CST) to investigate the effects of ipsilateral misprojections on voluntary movements and stereotypic locomotion. Null EphA4 mutations produce robust ipsilateral CST misprojections, resulting in bilateral corticospinal tracts. We hypothesize that a unilateral voluntary limb movement, not a stereotypic locomotor movement, will become a bilateral movement in EphA4 knock-out mice with a bilateral CST. However, in EphA4 full knock-outs, spinal interneurons also develop bilateral misprojections. Aberrant bilateral spinal circuits could thus transform unilateral corticospinal control signals into bilateral movements. We therefore studied mice with conditional forebrain deletion of the EphA4 gene under control by Emxl, a gene expressed in the forebrain that affects the developing CST but spares brainstem motor pathways and spinal motor circuits. We examined two conditional knock-outs targeting forebrain EphA4 during performance of stereotypic locomotion and voluntary movement: adaptive locomotion over obstacles and exploratory reaching. We found that the conditional knock-outs used alternate stepping, not hopping, during overground locomotion, suggesting normal central pattern generator function and supporting our hypothesis of minimal CST involvement in the moment-to-moment control of stereotypic locomotion. In contrast, the conditional knock-outs showed bilateral voluntary movements under conditions when single limb movements are normally produced and, as a basis for this aberrant control, developed a bilateral motor map in motor cortex that is driven by the aberrant ipsilateral CST misprojections. Therefore, a specific change in CST connectivity is associated with and explains a change in voluntary movement.

Key words: corticospinal tract; EphA4; locomotion; motor cortex; reaching

\section{Introduction}

Genetic tools are used to investigate the circuits driving motor behavior. Gene ablation studies have produced spinal interneuron development impairments that lead to distinctive locomotor phenotypes in maturity. Locomotor circuit development, for example, depends on the axon guidance molecule ephrinB3 and its receptor, EphA4. In spinal cord, ephrinB3 is a midline axon re-

Received Nov. 18, 2013; revised March 2, 2014; accepted March 6, 2014.

Author contributions: N.S., S.P., R.K., K.K., and J.H.M. designed research; N.S., S.P., T.S., and M.F. performed research; N.S., S.P., T.S., M.F., and J.H.M. analyzed data; N.S. and J.H.M. wrote the paper.

This work was supported by National Institutes of Health (Grants R01NS036835 and R01NS079569 to J.H.M.), the Max-Planck Society and the Deutsche Forschungsgemeinschaft (Grant SFB870 to R.K.), and the Swedish Medical Research Council, Hållsten, Ländells, and Swedish Brain Foundations (to K.K.). K.K. is a Royal Swedish Academy of Sciences Research Fellow supported by a grant from the Knut and Alice Wallenberg Foundation. We thank Xiuli Wu for histochemistry and histology, Aarathi Balijepalli for help with behavioral analysis, Lice Ghilardi and Kathleen Friel for statistical consulting, and Trevor Drew for comments on the manuscript.

The authors declare no competing financial interests.

Correspondence should be addressed to John H. Martin, PhD, Department of Physiology, Pharmacology, and Neuroscience, City College of the City University of New York, 160 Convent Avenue, New York, NY 10031. E-mail: jmartin@ccny.cuny.edu.

DOI:10.1523/JNEUROSCI.4848-13.2014

Copyright $\odot 2014$ the authors $\quad 0270-6474 / 14 / 345211-11 \$ 15.00 / 0$ pellant protein (Kullander et al., 2001b). Elimination of ephrinB3, EphA4, or the adapter protein $\alpha 2$-Chimaerin results in aberrant bilaterally projecting spinal interneurons (Kullander et al., 2001a; Yokoyama et al., 2001; Kullander et al., 2003; Beg et al., 2007; Iwasato et al., 2007; Wegmeyer et al., 2007; Asante et al., 2010), many of which are central pattern generator (CPG) components (Kiehn and Butt, 2003). Instead of an alternating gait during overground and treadmill locomotion, null mutants have a hopping gait (Akay et al., 2006). This is consistent with the obligatory involvement of CPGs in stereotypic limb locomotion that, after developing an aberrant bilateral organization, gains an aberrant bilateral motor function.

Goal-directed voluntary movements, which are neither stereotypic nor repetitive, have only begun to be a focus of genetic studies. Voluntary movements, which depend on supraspinal control, particularly the motor cortex and corticospinal tract (CST; Alstermark and Isa, 2012), are produced by limb kinematic changes that adaptively meet task demands (Ghez et al., 1991). Whereas the CST's involvement in voluntary control is well known, there is little evidence for how the pattern of CST spinal cord projections influences an individual's capability to perform 
voluntary movements. In this study, we took advantage of the role of EphA4 in determining the contralateral spinal projection of the CST. Null mutations of EphA4 produce robust ipsilateral CST misprojections, resulting in bilateral CSTs (Dottori et al., 1998; Coonan et al., 2001; Beg et al., 2007; Wegmeyer et al., 2007), as does forebrain EphA4 deletion (Paixao et al., 2013). We hypothesize that a unilateral voluntary limb movement, not a stereotypic locomotor movement, will become a bilateral movement in EphA4 knock-out mice with a bilateral CST. Because spinal interneurons also develop bilateral misprojections in EphA4 full knock-outs (Kiehn and Butt, 2003; Paixao et al., 2013), aberrant bilateral spinal circuits could transform unilateral corticospinal signals into bilateral movements. We therefore studied mice with conditional forebrain deletion of the EphA4 gene under control by Emx1, a gene expressed in the forebrain that affects the developing CST but spares brainstem motor pathways and spinal motor circuits.

We examined two conditional knock-outs targeting forebrain EphA4 (Filosa et al., 2009; Herrmann et al., 2010) during performance of voluntary movement, including adaptive locomotion over obstacles and exploratory reaching and stereotypic locomotion. We report that the conditional knock-outs used alternate stepping, not hopping, during overground locomotion, suggesting normal CPG function and supporting our hypothesis of minimal CST involvement in producing stereotypic locomotion. In contrast, the conditional knock-outs showed bilateral voluntary movements and, as a basis for aberrant control, developed a bilateral motor map in motor cortex driven by aberrant ipsilateral CST misprojections. Therefore, a specific change in CST connectivity is associated with and explains a change in voluntary movement.

\section{Materials and Methods}

Procedures and animal care

All procedures and animal care were approved by the Institutional Animal Care and Use Committees of City College of the City University of New York, the New York State Psychiatric Institute, Columbia University, in accordance with the European Community Council Directive of 24 November 1986 (86/609/EEC) and were approved by the ethics committee in charge of animal experimentation at the Regierung von Oberbayern (number 552-1-54-2531-24-10).

\section{Mice}

Experiments were conducted on adult male and female mice. Five animal groups were used: (1) A conditional knock-out of EphA4 in which both EphA4 alleles are conditionally excised under the control of the Emx1 promoter, which is expressed in the forebrain (Gorski et al., 2002; referred to as Emx1-Cre;EphA4 ${ }^{\mathrm{tm} 2 \mathrm{Kldr}}$, Filosa et al., 2009). This mouse was provided as a heterozygous line by one of the authors (K.K.). Heterozygous founders were bred and the homozygous offspring were identified through tail DNA PCR protocols. (2) A control for Emx1-Cre; EphA4 ${ }^{\text {tm2Kldr }}$ mice in which there is no conditional deletion (referred to as EphA4 ${ }^{\text {tm2Kldr }}$ ). (3) Another conditional knock-out of EphA4 in which one EphA4 allele is conditionally excised under the control of the Emx1 promoter and the other is deleted (referred to as Emx1-Cre; EphA4 ${ }^{\text {tm1Bzh}}$; Filosa et al., 2009; Herrmann et al., 2010; Paixao et al., 2013). (4) A control for the Emx1-EphA4 ${ }^{\text {tm1Bzh }}$ mice in which there is deletion of one allele and no conditional deletion of the second (referred to as EphA $4^{\text {tm1Bzh }}$ ). (5) C5BL/6 wild-type (WT) mice, which were purchased from The Jackson laboratory.

We compared performance of both conditional knock-outs in a series of behavioral tasks (overground locomotion, stereotypic treadmill locomotion, adaptive locomotion over obstacles, and exploratory reaching behavior) and electrophysiological assessments of the motor cortex. CST tracing was conducted in the Emx1-Cre;EphA4 ${ }^{\mathrm{tm} 2 \mathrm{Kldr}}$ mouse only. The CST has been traced in the Emx1-Cre;EphA4 ${ }^{\mathrm{tm} 1 \text { Bzh }}$ (Paixao et al., 2013).
Data from the conditional EphA4 knock-out mice were compared with WT and/or their nonconditionally deleted controls, which might have altered EphA4 expression.

\section{Anatomical tracing}

For corticospinal axon tracing in Emx1-Cre;EphA4 ${ }^{\mathrm{tm} 2 \mathrm{Kldr}}$ mice $(n=5$ for knock-out and $n=5$ for WT), we adapted with minor changes our published protocol (Asante and Martin, 2013). Surgery was performed under general anesthesia with a mixture of ketamine/xylazine (100 $\mathrm{mg} / 10 \mathrm{mg} / \mathrm{kg}$, i.p). The animals were placed in a stereotaxic frame (Kopf Instruments) and body temperature was maintained at $37^{\circ} \mathrm{C}$ by a warming plate (Physitemp TCAT-2LV; Kopf Instruments). Mice were administrated an analgesic (Rimadyl, $5 \mathrm{mg} / \mathrm{kg}$, s.c). The motor cortex was exposed by craniotomy, and a total of $600 \mathrm{nl}(200 \mathrm{nl} \times 3$ injections separated by $400 \mu \mathrm{m}$ ) of $10 \%$ biotinylated dextran amine (BDA; 10,000 MW; Molecular Probes) was injected unilaterally in the forelimb area. The locations were, from bregma: $\mathrm{AP}=0.4 \mathrm{~mm} ; \mathrm{ML}=1.2,1.6,2 ; \mathrm{DV}=$ 0.8 . The injections were made using a pulled glass pipette with a tip diameter of $\approx 20 \mu \mathrm{m}$ and a micropump injector (UMP3; World Precision Instruments) at a speed of $3 \mathrm{nl} / \mathrm{s}$. After injection, the pipette was kept in place for an additional $5 \mathrm{~min}$ to avoid leakage of containing solution.

To retrogradely trace brainstem spinal-projecting neurons and spinal interneurons, we exposed the caudal cervical and rostral thoracic vertebrae following standard aseptic surgical procedures (cervical spinal cord: $n=5$ for knock-out Emx1-Cre;EphA $4{ }^{\text {tm2Kldr }}$ and $n=5$ for WT; lumbar spinal cord: $n=5$ for knock-out and $n=5$ for WT; $n=3$ for control EphA4 $\left.{ }^{\text {tm2Kldr }}\right)$. We used the long spinous process of the second thoracic vertebra (T2) as a reliable landmark and to fixate the vertebral column. The $\mathrm{T} 2$ process was slightly elevated and gently stretched caudally to flatten the curvature of the cervical spine to provide better exposure and to facilitate intraspinal injection. After the spinal surgical procedures, 300 $\mathrm{nl}$ of the retrograde tracer dextran tetramethylrhodamine (RDA; 3000 MW; Invitrogen) was infused unilaterally at $500 \mu \mathrm{m}$ from the midline and $500 \mu \mathrm{m}$ below the pia mater through a 34 ga beveled needle (UMP3; World Precision Instruments) at an injection rate of $2 \mathrm{nl} / \mathrm{s}$. After the injection, the needle was kept in place for an additional $3 \mathrm{~min}$ to avoid leakage of tracer. Similar procedures were followed to retrogradely label brainstem and spinal interneuron projections in lumbar spinal cord injection. We used the first lumbar vertebra (L1) as a landmark. The dura was exposed between the Th13 and L1 vertebrae. After spinal injections, mice were removed from fixation and the wound was closed by approximating the paraspinal muscles and suturing the skin.

For CST anterograde tracing ( $n=5$ in each group), mice were killed after 2 weeks by an overdose of anesthetic followed by perfusion with $4 \%$ paraformaldehyde. Frozen coronal sections of spinal cord and brain (40 $\mu \mathrm{m}$ ) were cut for visualization of BDA-labeled CST fibers projections. Free-floating sections were incubated at room temperature for $1 \mathrm{~h}$ in incubating buffer ( $0.1 \mathrm{M}$ PBS with 3\% donkey serum) containing ExtrAvidin Cy3 (1:3000; Sigma). After rinsing, sections were mounted on gelatin-coated slides, air dried overnight, and cover slipped.

For retrograde tracing, 3-5 d after injection, animals were administered an anesthetic overdose and tissue removed, as with the anterograde studies. Frozen horizontal sections $(40 \mu \mathrm{m})$ of spinal cord were cut for visualization of RDA-labeled spinal interneurons. Coronal sections (40 $\mu \mathrm{m}$ ) of the brainstem were cut to visualize the red nuclei and reticular formation nuclei.

\section{Electrophysiology procedures}

Intracortical stimulation of motor cortex. For motor cortex (M1) stimulation experiments, we used similar parameters to a previous stimulation study of cortical control of adaptive locomotion in the mice (Asante et al., 2010). Briefly, we used tungsten microelectrodes (Microprobe; $0.1 \mathrm{M} \Omega$ impedance, $0.081 \mathrm{~mm}$ shaft diameter, $1-2 \mu \mathrm{m}$ tip diameter) and electrode penetrations were made perpendicular to the pial surface at the depths $0.8-1.0 \mathrm{~mm}$. In all animals, the stimulated region was identical: between 0.0 and $2.4 \mathrm{~mm}$ lateral to bregma and up to $2 \mathrm{~mm}$ rostral to bregma. Stimuli ( $45 \mathrm{~ms}$ duration train, $330 \mathrm{~Hz}, 0.2 \mathrm{~ms}$ biphasic; every $2 \mathrm{~s}$ ) were delivered using a constant current stimulator (Model 2100; A-M Systems). The threshold was defined as the lowest current that produced 
a contralateral motor effect. Maximal current of $100 \mu \mathrm{A}$ was used. If no response was evoked at or below $100 \mu \mathrm{A}$, the site was considered nonresponsive.

Electromyography recordings. We recorded responses evoked from the biceps bilaterally using percutaneous Ni-chrome wire electrodes (deinsulated $1 \mathrm{~mm}$ from the tip) in response to motor cortex stimulation. Electromyography (EMG) recordings were made with a differential AC amplifier with low- and high-pass filtration (Model 1700; A-M Systems). EMG recording wires were inserted using a 27 ga hypodermic needle guide. We recorded differentially, with two wire electrodes within each muscle and a separate ground. We verified adequacy of EMG recording and muscle placement by noting increased EMG activity with passive elbow extension. Because we recorded from the two hemispheres in each animal, we were able to verify that the absence of an ipsilateral response was not due to an inferior recording, because the same EMG electrodes were also used to record a contralateral-evoked response.

EMG signals were acquired using an analog-to-digital converter (CED) and processed using the program Signal (version 5.01; CED). Averages of rectified EMG were generated from each animal and then group averages were computed for all animals within each group. To further quantify results, we developed a laterality index that corresponded to the integrated ipsilateral EMG value divided by the integrated contralateral EMG value for EMG averages for each animal (Paixao et al., 2013). For each cortical stimulation site, the time window we used for integration of EMG responses was the same for the ipsilateral and contralateral responses. The time window varied for each animal depending on the latency and form of the response. Strongly contralateral responses have a laterality index that is close to zero and bilateral responses, close to one.

\section{Anatomical data acquisition and analysis}

For anterograde tracing, images were acquired on a Nikon inverted microscope under identical conditions of magnification, illumination, and exposure to minimize variability. Images were converted to black and white format in Adobe Photoshop and underwent a digital analysis using a selective threshold adjustment to highlight only BDA-labeled axons, as in our previous studies (Tan et al., 2012; Asante and Martin, 2013). These images were then used to determine changes in ipsilateral and contralateral CST fibers projections in WT and Emx1-Cre;EphA4 ${ }^{\mathrm{tm} 2 \mathrm{Kldr}}$ mice. Axon distributions within the gray matter were analyzed in five transverse sections for each mouse. Digital analysis of individual sections were corrected for orientation and aligned with one another according to fiduciary marks (intersection between the gray matter above the central canal and the dorsal median septum). Photoshop TIFF files of individual sections of the spinal gray matter were skeletonized using ImageJ before export and analyzed using custom programs written in MATLAB (The MathWorks), as described previously (Friel et al., 2012). Skeletonization reduces the width of all labeled axons to 1 pixel and thus allows our measurements to accurately represent local axon length and density not axon diameter. For analysis, TIFF files of individual sections of the spinal gray matter were divided into $80 \times 80 \mu \mathrm{m}^{2}$ regions of interest (ROIs). For each ROI, we computed the mean density of BDA-labeled axons (i.e., the number of pixels). A matrix of mean axon density was generated in MATLAB that preserved the mediolateral and dorsoventral dimensions of the distribution of CST fibers labeled in the gray matter. In this study, the mediolateral distributions of CST labeling were generated for individual animals and then averaged for all animals within each group. To normalize for differences in the size of the gray matter across animals, all graphs were interpolated to 100 points between the contralateral and ipsilateral borders of the cervical gray matter.

Our anatomical data were corrected for the variability in tracing differences between animals by using an ROI within the CST in the ventral dorsal columns. Using the program Neurolucida (MBF Bioscience), we counted the number of BDA-labeled axons within a $25 \times 25 \mu \mathrm{m}^{2}$ ROI contralateral to the cortical injection side. We divided individual section data (number of BDA-labeled axons of contralateral and ipsilateral gray matter) by the average of the estimated number of dorsal column axons per animal. The average of each animal was then divided by the average of the group to generate the correction factor. To analyze CST laterality, we first quantified the total number of the CST-labeled axons within the gray matter. We divided the number of BDA-labeled axons measured on the ipsilateral side by the total number of BDA-labeled axons in the gray matter.

For retrograde tracing, images (4-6 sections/animal) were acquired using an Olympus BX60 microscope. Labeled spinal neurons were counted within the forelimb enlargement $(\mathrm{C} 7 / \mathrm{C} 8)$ or, for the lumbar injections, in the lumbar enlargement (L2/L3). For both conditions, contralateral and ipsilateral positive spinal neurons ( 6 sections per animal) were counted $\sim 2 \mathrm{~mm}$ from the injection site into a $600 \times 400 \mu \mathrm{m}^{2}$ ROI. Retrogradely labeled neurons were counted in the red nucleus and in reticular nuclei. Dark-field microscopy was used to aid in identification of nuclear regions.

\section{Training and behavioral testing}

We focused on performance in two voluntary motor tasks: exploratory reaching (Schallert et al., 2000; Starkey et al., 2005) and adaptive locomotion over obstacles mounted on a treadmill (Drew et al., 2008; Asante et al., 2010). Adaptive locomotion was compared with stereotypic overground locomotion and unobstructed treadmill locomotion. We also screened for impairments in the sticky tape test to assess somatic sensoryguided forelimb movements and grid walking and the ability to coordinate limb placement during spontaneous locomotion (Starkey et al., 2005). The Emx1-Cre;EphA4 ${ }^{\mathrm{tm} 1 \mathrm{Bzh}}$ mice and their floxed controls $\left(\right.$ EphA $\left.4^{\mathrm{tm} 1 \mathrm{Bzh}}\right)$ were studied in Munich, Uppsala, and New York; the Emx1-Cre;EphA4 ${ }^{\text {tm2Kldr }}$ mice, their floxed controls (EphA4 ${ }^{\text {tm2Kldr }}$ ), and WT mice were studied in New York. Performance was videotaped and analyzed by manual inspection using the program iMovie (Apple) on a frame-by-frame basis for the presence of alternate stepping or hopping during locomotion and unilateral or bilateral reaching. For analyses, experimenters were blinded to genotype group.

Locomotor behavior. Treadmill adaptive locomotion was performed at 3 treadmill speeds $(6 \mathrm{~cm} / \mathrm{s} ; 9 \mathrm{~cm} / \mathrm{s} ; 17 \mathrm{~cm} / \mathrm{s})$ and at 2 obstacle heights $(0.5$ $\mathrm{cm}$ and $1.0 \mathrm{~cm}$ ), as described previously (Asante et al., 2010). For comparison, locomotor behavior was compared during stereotypic over ground locomotion when the treadmill belt was stationary and unobstructed treadmill locomotion (at the same speeds as for adaptive locomotion).

Reaching exploratory behavior. We assessed skilled forelimb reaching by placing the mouse in a clear glass cylinder (Pyrex, $25 \times 18 \mathrm{~cm}$ diameter). The mouse was allowed to acclimate for $2 \mathrm{~min}$ in the testing environment before recording movements. When placed in the cylinder, motivated mice engage in exploratory behavior and reach to contact the wall with their forepaws. Some mice that displayed less motivation to reach the wall were fed after testing. To facilitate movements toward the cylinder wall, a food pellet was suspended from the top of the cylinder. After each session, we recorded the number of independent wall contacts observed for the right, left, and both forelimbs simultaneously. We collected 30 reaching movements for each session.

Sticky tape test. We applied a $0.3 \times 0.2 \mathrm{~cm}$ piece of adhesive tape to the midline of the nose of each mouse and the mouse was placed in the testing chamber. The stimulus provokes the mouse to bring its paws toward the tape and remove it from the nose. The testing period was conducted over a 15-30 min period and the number of independent and simultaneous forelimb movements was recorded. A total of 30 swiping movements were analyzed.

Grid walking. We assessed skilled walking on a grid floor $\left(19 \times 19 \mathrm{~cm}^{2}\right.$, $0.8 \times 0.8 \mathrm{~cm}^{2}$ grid squares) placed above a glass surface. Before video recording, the mouse was allowed to traverse the grid floor freely for 2 min. The mouse was filmed from below over a $15 \mathrm{~min}$ time period and the number of errors made with the forelimbs was scored. A forelimb placement error was counted when the paw slipped through the grid opening. A total number of 30 step cycles (alternating steps or hops) were scored.

\section{Western blotting}

Dissection of motor cortex and cervical spinal cord. Animals were administered an overdose of anesthesia and the brain and spinal cord were removed and submerged in ice-cold artificial CSF (ACSF) within 2 min. 
We placed the brain and spinal cord on a microscope slide $(75 \times 50 \times 1$ $\mathrm{mm}$ ) containing 2.5 -cm-diameter Whatman filter paper dampened with ACSF. The slide was placed on an ice-cold metal plate to ensure that the tissue remained cold. We dissected the frontal cortices and the cervical spinal cord from the remaining tissue. Frontal cortex and spinal tissue samples were either used immediately or collected in dry ice and stored at $-80^{\circ} \mathrm{C}$ for later use.

Protein extraction and blots analysis. Tissues were extracted from mutants and control mice and homogenized in ice-cold MAP kinase buffer containing the following (in mM): 20 Tris- $\mathrm{HCl}, \mathrm{pH} 7.4,20 \mathrm{NaCl}, 1 \mathrm{EDTA}$, 1 EGTA, $20 \mathrm{NaF}, 25 \beta$-glycerophosphate, 5 sodium pyrophosphate plus $1 \%$ Triton X-100 and supplemented with a protease inhibitor mixture containing $1 \mathrm{~mm}$ PMSF, $1 \mathrm{~mm} \mathrm{Na} \mathrm{VO}_{4}, 1 \mathrm{~mm}$ DTT, $2 \mu \mathrm{g} / \mathrm{ml}$ aprotinin, 2 $\mu \mathrm{g} / \mathrm{ml}$ leupeptin, and $2 \mu \mathrm{g} / \mathrm{ml}$ pepstatin. Concentrations were estimated with the Bio-Rad protein assay reagent and following the microassay procedure. Thirty micrograms of protein per sample were separated by SDS-PAGE and transferred onto a nitrocellulose membrane (Bio-Rad). Proteins were probed by immunoblotting with the primary antibodies actin mouse monoclonal antibody (1:10,000, ab3280; Abcam) and EphA4 mouse monoclonal antibody (A1:5000, anti-EphA4/Sek; BD Biosciences) and the secondary antibody: peroxidase-goat anti-mouse IgG (1:50,000; Life Technologies). Immunodetection was performed using SuperSignal West Pico Chemiluminescent Substrates (Thermo Scientific). Western blots were quantified using ImageJ software. Optical density values were normalized to actin signal. For EphA4, the band at 130 $\mathrm{kDa}$ was quantified and, for actin, the band at $42 \mathrm{kDa}$ was quantified.

\section{Genotyping}

Emx1-Cre;EphA4 ${ }^{\text {tm1Bzh }}$ mice (and their floxed controls, EphA4 ${ }^{\mathrm{tm} 1 \mathrm{Bzh}}$ ) were genotyped as described previously (Paixao et al., 2013). We genotyped Emx1-Cre;EphA4 ${ }^{\text {tm2Kldr }}$ (and their floxed controls, EphA4 ${ }^{\text {tm2Kldr; }}$; Filosa et al., 2009) at postnatal day 10 by PCR using Cre forward (ACG AGT GAT GAG GTT CGC AAG A), Cre reverse (ACC GAC GAT GAA GCA TGT TTA G), EphA4 loxp forward (GGG CGC ACA GTA ATT TTC TT) and EphA4 loxp reverse primers (ATC ACG TTG CAC ACC TGG TA; Eurofins MWG operon; Integrated DNA Technologies).

\section{Statistical analysis}

All statistical tests were performed with GraphPad Prism software version 5.0. Parametric tests were used whenever possible; nonparametric tests were used when $n<10$. Intergroup comparisons were tested with either a one-way-ANOVA with group as the independent factor and Bonferroni post hoc analysis (for parametric data) or with the KruskalWallis test and Dunns post hoc analysis (for nonparametric data). Comparison between two groups was evaluated by either using a $t$ test or the Mann-Whitney analysis. All data are presented as the mean \pm SEM. $p<$ 0.05 was considered statistically significant.

\section{Results}

\section{Overview of experiments}

All experiments were conducted on Emx1-Cre;EphA4 ${ }^{\mathrm{tm} 2 \mathrm{Kldr}}$ mice. First, we determined the reduction in cortical EphA4 protein levels produced by conditional forebrain gene deletion. Next, we used a sensitive retrograde anatomical assay to verify the absence of changes in the laterality of brainstem descending and spinal motor circuits. On this background of changes selective for the corticospinal system, we examined the differential effects on bilateral forelimb voluntary and stereotypic locomotor movements. Finally, we assessed ipsilateral CST misprojections and the motor cortex representation of muscle activation and forelimb movement. Additional selected experiments were conducted on a second conditional EphA4 knock-out mouse (Emx1-Cre; EphA $\left.4^{\mathrm{tm} 1 \mathrm{Bzh}}\right)$, including Western blot, behavioral, and motor cortex electrophysiology, to further our understand of the interplay between EphA4 protein levels in motor cortex in the production of bilateral voluntary movements and the laterality of the motor cortex motor representation. CST tracing was not per- formed in the Emx1-Cre;EphA4 ${ }^{\mathrm{tm} 1 \mathrm{Bzh}}$ mice because this has been reported previously (Paixao et al., 2013).

\section{Changes in EphA4 protein levels after conditional gene ablation}

We investigated EphA4 expression in the motor cortex and the cervical spinal cord from conditional knock-out and WT mice using Western blot analysis. Motor cortex lysates from the conditional knock-out Emx1-Cre;EphA4 ${ }^{\mathrm{tm} 2 \mathrm{Kldr}}$ mice (Fig. $1 A$ ) expressed a significantly lower amount of EphA4 protein than WT mice (Fig. 1C). Comparison with Emx1-Cre;EphA4 ${ }^{\text {tm1Bzh }}$ mice (Fig. 1A) revealed a significantly larger reduction in EphA4 protein levels in the Emx1-Cre;EphA4 ${ }^{\mathrm{tm} 2 \mathrm{Kldr}}$ mice (Fig. 1D). In contrast to the large reduction in EphA4 protein levels in cortex (Emx1-Cre;EphA4 ${ }^{\mathrm{tm} 2 \mathrm{Kldr}}$ mice, $86 \%$; Emx1-Cre;EphA4 ${ }^{\mathrm{tm} 1 \mathrm{Bzh}}$ mice, $74 \%$ ), there was a much smaller reduction in the cervical spinal cord (Emx1-Cre;EphA4 ${ }^{\mathrm{tm} 2 \mathrm{Kldr}}$ mice, 26\%; Emx1-Cre; EphA $4{ }^{\mathrm{tm} 1 \mathrm{Bzh}}$ mice, $25 \%$; Fig. $1 \mathrm{~B}, E$ ) that was not significant (oneway ANOVA, Kruskal-Wallis test, $p=0.232$ ). The spinal reduction might reflect the substantial reduction in EphA4 protein in CST axons in the cervical dorsal columns or the loss of EphA4 in spinal neurons showing ectopic expression of Emx1 (Galley and Clowry, 2010). Further evidence that conditional gene deletion did not significantly affect spinal EphA4 protein levels comes from anatomical analysis of the cervical spinal cord structure. It has been reported that EphA4 full mutants have a shallow dorsal column and an expanded dorsoventral midline extent of lamina 10 (Kullander et al., 2001b). This morphological change was quantified as the distance between the dorsal spinal cord surface and the base of the dorsal column divided by the distance between the dorsal spinal cord surface and the central canal (Paixao et al., 2013). This measure did not change in the Emx1-Cre;EphA4 ${ }^{\mathrm{tm} 1 \mathrm{Bzh}}$ and EphA4 ${ }^{\mathrm{tm} 1 \mathrm{Bzh}}$ (ratio $=0.9$ for both groups; Paixao et al., 2013), but was somewhat smaller in the Emx1-Cre;EphA4 ${ }^{\mathrm{tm} 2 \mathrm{Kldr}}$ mice than in WT and control mice $\left(\right.$ Emx1-Cre;EphA $4{ }^{\mathrm{tm} 2 \mathrm{Kldr}}=0.77 \pm 0.03 ; \mathrm{WT}$ mice $=0.91 \pm$ 0.009; EphA $4^{\mathrm{tm} 2 \mathrm{Kldr}}$ mice $=0.91 \pm 0.01$, Kruskal-Wallis test, $p=$ 0.008). For comparison, EphA4 elimination in the spinal cord (Lbx1-EphA4 KO) or the full EphA4 KO results in a substantial and consistent morphological change $(\mathrm{Lbx} 1 \mathrm{KO}=0.45$; full $\mathrm{KO}=0.5$; Paixao et al. (2013)).

We investigated EphA4 expression in a separate cohort of control mice: WT mice, EphA4 ${ }^{\text {tm2Kldr }}$ mice without conditional deletion, and EphA $4{ }^{\mathrm{tm} 1 \mathrm{Bzh}}$ mice in which there is deletion of one allele and no conditional deletion of the second. For these controls, there were no significant differences in protein levels in cortex between the EphA $4^{\mathrm{tm} 2 \mathrm{Kldr}}$ and WT mice (Mann-Whitney test, $p=0.23$ ) or between the two conditional mutants (MannWhitney test, $p=0.1$ ) or between the two mutants and WT mice in the cervical spinal cord $(n=3-4$; Kruskal-Wallis test, $p=$ 0.41 ). To summarize, in the conditional knock-out mice we found substantial and differential EphA4 reductions in cortex but no significant change in the spinal cord. The small and insignificant EphA4 reduction in the cervical spinal cord did not correlate with a morphological change in the cord as there were no EphA4 differences between the two conditional knock-out mice, but there was a small morphological difference in the Emx1-Cre; EphA4 ${ }^{\text {tm2Kldr }}$ mice.

\section{Characterization of conditional EphA4 ablation}

As described previously, complete elimination of EphA4 in the spinal cord results in misprojection of the axons of spinal interneurons(Kullander et al., 2003; Butt et al., 2005; Paixao et al., 
A Motor cortex

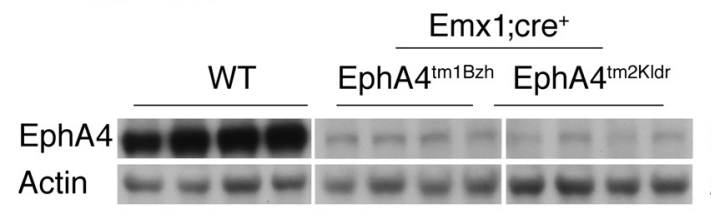

C

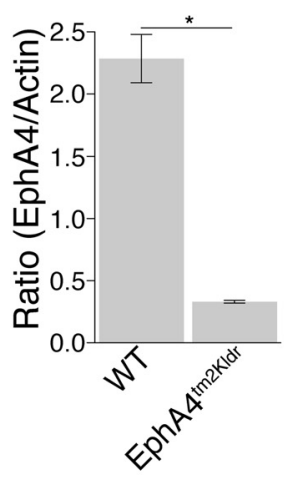

${\mathrm{Emx} 1 ; \mathrm{cre}^{+}}^{+}$
D

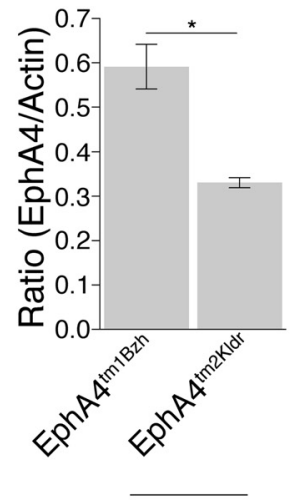

Emx1; cre $^{+}$
B Cervical spinal cord
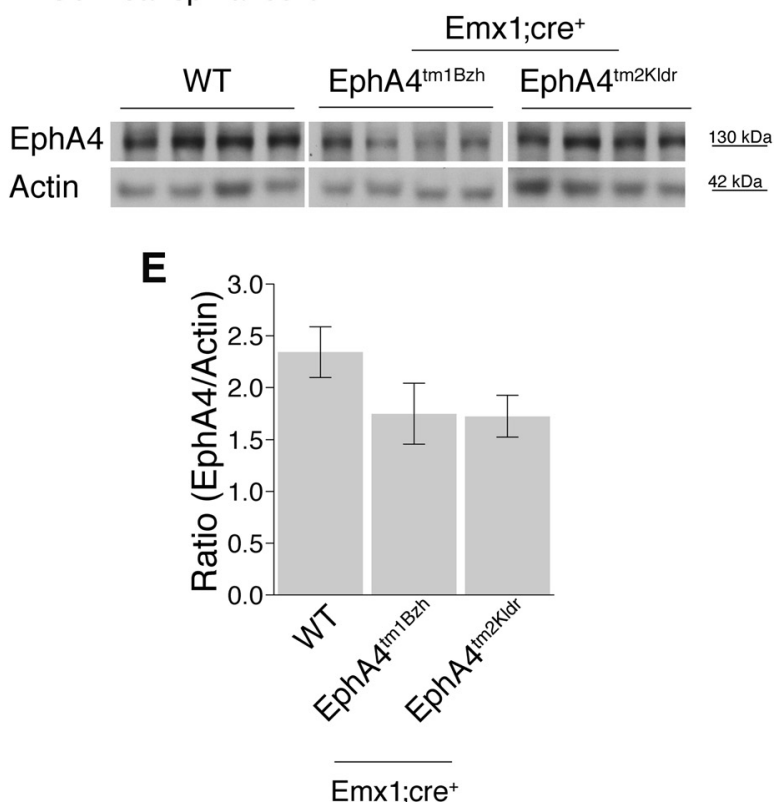

Figure 1. Conditional elimination of EphA4 in the forebrain but not the cervical spinal cord. Immunoblotting analysis of motor cortex lysates shows decreased levels of EphA4 expression between wild-type and the two EphA4 conditional mutants $(\boldsymbol{A})$, but minimal reductions in the cervical spinal cord $(\boldsymbol{B})$. Lanes show data from individual mice $(\boldsymbol{A}, \boldsymbol{B})$. EphA4 was localized at $130 \mathrm{kDa}$ and actin was localized between molecular weight markers at 55 and $35 \mathrm{kDa}$. Exposure times for gels were as follows: motor cortex EphA4, $20 \mathrm{~s}$; actin, $6 \mathrm{~s}$; cervical spinal cord, $60 \mathrm{~s}$, actin, $6 \mathrm{~s}$. $\boldsymbol{C}-\boldsymbol{E}$, Bars plot ratio of mean ( \pm SE) EphA4 and Actin protein levels for each group ( $n=4-5$ mice/group). There is a significant reduction of EphA4 protein level in the motor cortex of homozygous Emx1-Cre; EphA4 ${ }^{\mathrm{tm} 2 \mathrm{Kldr}}$ compared with WT (C; $p=0.029$, Mann-Whitney test). This reduction is more pronounced in the Emx1-Cre;EphA4 ${ }^{\mathrm{tm} 2 \mathrm{Kldr}}$ than the Emx1-Cre;EphA4 ${ }^{\mathrm{tm} 1 \mathrm{Bzh}}$ mutant $(\boldsymbol{D} ; p=0.028$, Mann-Whitney test). Immunoblotting analysis from cervical spinal cord lysates showed similar protein level in wild-type and two EphA4 conditional mutants ( $p=0.232$, Kruskal-Wallis test, Dunn's posttest: $p>0.05 ; n=4 /$ group).

2013). To determine whether this occurred after conditional EphA4 elimination in the forebrain, we used retrograde labeling to examine differences in intraspinal projections of spinal interneurons in Emx1-Cre;EphA4 ${ }^{\mathrm{tm} 2 \mathrm{Kldr}}$ and WT mice. We unilaterally injected a fluorescent tracer (rhodamine-dextran amine) into the $\mathrm{C} 8$ segment and verified postmortem that there was no spread of tracer across the midline (Fig. 2A). Counts of the number of ipsilateral- and contralateral-labeled interneurons revealed no significant differences between the mutant and wild-type mice (Fig. 2D). In a separate cohort of mice, we injected tracer into L2/L3 and again found no significant differences in the number of ipsilateral and contralateral interneurons in the Emx1-Cre; EphA $4^{\mathrm{tm} 2 \mathrm{Kldr}}$ and wild-type mice (Mann-Whitney test, $p=$ $0.27)$.

To determine whether EphA4 elimination in the forebrain affected the laterality of brainstem neurons with axons that descend to the cervical spinal cord, we compared the number of retrogradely labeled neurons in the red nucleus and pontomedullary reticular formation in Emx1-Cre;EphA $4^{\mathrm{tm} 2 \mathrm{Kldr}}$ and wildtype mice after $\mathrm{C} 8$ tracer injection (Fig. $2 B, C, E, F$ ). Knock-out and WT mice showed similar and strong contralateral labeling of neurons in the red nucleus (Fig. $2 B, E$ ). Whereas labeled neurons in the pontomedullary reticular formation of WT mice have a bilateral distribution, there were no significant differences with Emx1-Cre;EphA4 ${ }^{\mathrm{tm} 2 \mathrm{Kldr}}$ mice (Fig. 2C,F). We also compared the numbers of ipsilateral and contralateral rubrospinal and reticulospinal neurons projecting to L2/L3 and there were no differences. The small and insignificant reduction in spinal EphA4 in Emx1-Cre;EphA4 ${ }^{\mathrm{tm} 2 \mathrm{Kldr}}$ mice was not associated with changes in the laterality of spinal interneurons or brainstem descending projection neurons. This suggests that conditional gene ablation affected cortical not brainstem or spinal motor pathways.

\section{Effects of conditional forebrain EphA4 elimination on stereotypic locomotor and voluntary forelimb motor behaviors}

We next compared motor performance in the two knock-out mice with control mice. For overground, unobstructed treadmill, and obstructed treadmill locomotion, we examined the occurrence of alternate stepping and hopping. We defined hopping as a simultaneous lift and landing of both forelimbs and/or hind limbs. During overground locomotion (Fig. $3 A$ ), there were no differences between conditional knock-out mice and WT mice: all stepped with their forelimbs nearly $100 \%$ of the time. During unobstructed treadmill locomotion (at a treadmill speed of 17 $\mathrm{cm} / \mathrm{s}$; Fig. $3 \mathrm{~B}$ ), the results showed a significant group effect because the Emx1-Cre;EphA $4{ }^{\mathrm{tm} 2 \mathrm{Kldr}}$ mice showed a small percentage of forelimb hopping for the same treadmill speed. We also examined hindlimb movements during overground locomotion and found no significant difference in the percentage of stepping versus hopping ( $n=6-10, p=0.08, F=2.9$, one-way ANOVA). During unobstructed treadmill locomotion, Emx1-Cre; EphA $4^{\mathrm{tm} 2 \mathrm{Kldr}}$ mice $(n=15)$ showed a small percentage of hopping compared with WT $(n=10)$ and Emx1-Cre;EphA4 ${ }^{\text {tm1Bzh }}$ mice $(n=6 ; p<0.0001, F=17.7$, one-way ANOVA, Bonferroni posttest, $p<0.05$ ). Whereas quantitative analyses of overground and unobstructed treadmill locomotion are based on assessment of 30 locomotor cycles (i.e., steps and hops) per session, we screened $\sim 2 \mathrm{~h}$ of video recordings in each mouse $(n=63 \mathrm{~h}$ total for combined knock-outs, controls, and WT). When forelimb hopping was observed (Fig. $3 B$ ), it was sporadic. Whereas we cannot rule out subtle circuit changes, our biochemical, retrograde interneuron, and behavioral findings suggest that forebrain elimination of EphA4 does not significantly affect development and action of spinal locomotor circuits. 
A Cervical spinal cord

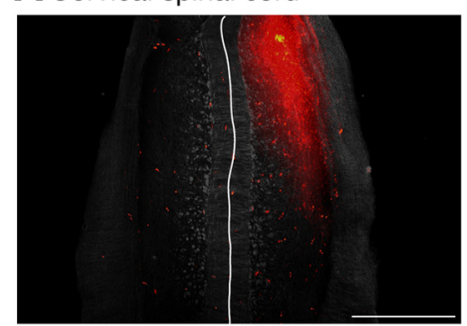

D

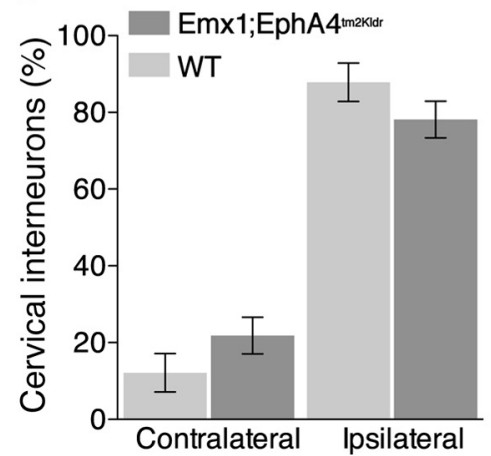

B Rubrospinal neurons

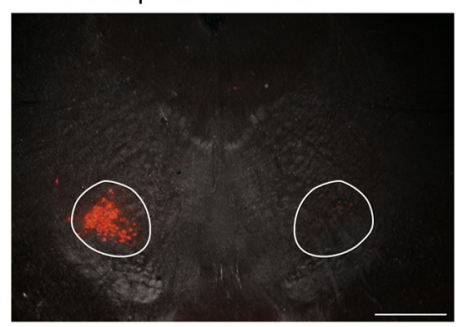

E

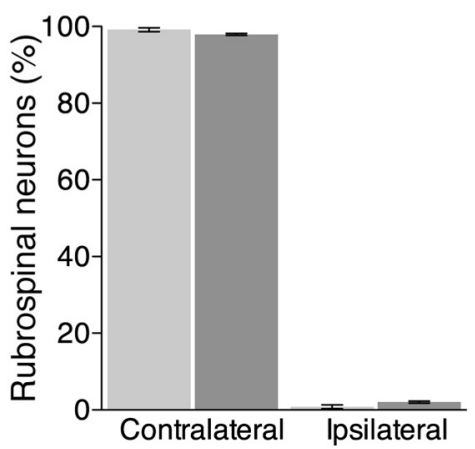

C Reticulospinal neurons

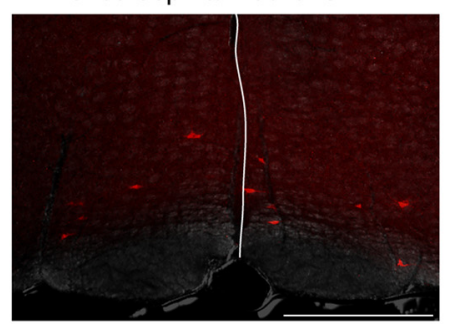

$\mathbf{F}$

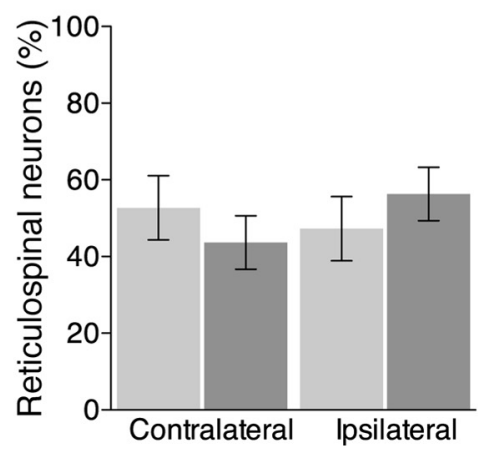

Figure 2. Laterality of spinal interneurons and brainstem neurons in Emx1-Cre;EphA4 ${ }^{\mathrm{tm} 2 \mathrm{KI} r}$ mice. $\boldsymbol{A}$, Overlapping dark-field and fluorescence images of the cervical spinal cord for a representative WT mouse highlighting the site of unilateral RDA injection and the labeling observed in the ipsilateral and contralateral C7/C8 segments. $\boldsymbol{B}, \boldsymbol{C}$, Similar to $A$, but for retrogradely labeled neurons in the red nucleus and medullary reticular formation. Rubrospinal neurons $(\boldsymbol{B})$ are located contralateral to the spinal injection site, whereas reticulospinal neurons are located bilaterally $(\boldsymbol{C})$. White lines mark the midline $(\boldsymbol{A}, \boldsymbol{C})$ and the border of the red nuclei $(\boldsymbol{B})$; calibrations: $500 \mu \mathrm{m}$. $\boldsymbol{D}-\boldsymbol{F}$, Mean percentage ( \pm SE) of labeled ipsilateral and contralateral neurons $(n=4$ mice/group) revealed no significant differences between Emx1-Cre;EphA4 ${ }^{\text {tm2KIdr }}$ and WT mice at all three levels (Mann-Whitney test, cervical cord: $p=0.23$; rubrospinal neurons: $p=0.2 ;$ reticulospinal neurons, contralateral and ipsilateral: $p=0.63)$.

Both conditional knock-outs revealed consistent and significant increases in hopping in obstructed treadmill locomotion compared with their respective controls (Fig. 3C,D). Performance was assessed at two obstacle heights and three treadmill velocities; only data for the $1 \mathrm{~cm}$ obstacle height are shown. For the Emx1-Cre;EphA $4^{\mathrm{tm} 1 \mathrm{Bzh}}$ mice, there was a significant increase (approximately a doubling) in the hopping rate for the forelimbs compared with controls (EphA $4^{\text {tm1Bzh }}$ ). The Emx1-Cre; EphA $4{ }^{\mathrm{tm} 2 \mathrm{Kldr}}$ mice further showed a doubling in hopping over the Emx1-Cre;EphA $4{ }^{\mathrm{tm} 1 \mathrm{Bzh}}$ mice. Neither conditional knock-out nor their respective controls showed differences between treadmill velocities. Further, the Emx1-Cre;EphA4 ${ }^{\text {tm2Kldr }}$ mice showed a significant increase in hopping over EphA $4{ }^{\mathrm{tm} 2 \mathrm{Kldr}}$ controls and WT mice ( $p<0.0001$, one-way ANOVA; Fig. 3D).

Hindlimb hopping was similarly and significantly increased in both conditional knock-out mice, but not in controls and WT mice (Emx1-Cre;EphA4 ${ }^{\mathrm{tm} 1 \mathrm{Bzh}}$ vs EphA4 ${ }^{\mathrm{tm} 1 \mathrm{Bzh}}: F=9.12, p=$ 0.003 , with no differences between treadmill velocities, $F=0.2$, $p=0.82 ;$ Emx1-Cre;EphA4 ${ }^{\mathrm{tm} 2 \mathrm{Kldr}}$ vs WT: $F=204.8, p<0.0001$; no differences between treadmill velocities, $F=0.24, p=0.78$; Emx1-Cre;EphA4 ${ }^{\text {tm1Bzh }}$ vs Emx1-Cre;EphA4 ${ }^{\text {tm2Kldr }}: F=18.53$; $p<0.0001 ;$ Emx1-Cre;EphA4 ${ }^{\mathrm{tm} 2 \mathrm{Kldr}}$ vs EphA4 ${ }^{\mathrm{tm} 2 \mathrm{Kldr}}: p<$ 0.0001, one-way ANOVA, Bonferroni's posttest: WT vs EphA $4^{\text {tm2Kldr }}, p>0.05$, WT vs Emx1-Cre;EphA4 ${ }^{\text {tm2Kldr }}, p<$ $0.05)$.

Exploratory reaching (Fig. 3E) revealed that Emx1-Cre; EphA ${ }^{\text {tm2Kldr }}$ mice reached with both forelimbs significantly more than WT mice, which used more single forelimb movements. Surprisingly, we found no significant difference between Emx1-Cre;EphA4 ${ }^{\mathrm{tm} 1 \mathrm{Bzh}}$ and WT mice. Further, there were no significant differences in the other forelimb behavioral tests examined (sticky tape test or grid walking), suggesting no substan- tial impairment in motor coordination or somatic sensorymotor integration in these mice. Our findings show that mice carrying either allele demonstrate bilateral voluntary control, but that the Emx1-Cre;EphA4 ${ }^{\mathrm{tm} 2 \mathrm{Kldr}}$ mice express a stronger bilateral motor phenotype than the Emx1-Cre;EphA4 ${ }^{\text {tm1Bzh }}$ mice.

\section{Bilateral cervical CST terminations}

To determine the relationship between the occurrence of CST ipsilateral misprojections, hopping during obstructed locomotion, and bilateral exploratory reaching movements, we examined the laterality of CST projections. We recently showed that Emx1-Cre;EphA4 ${ }^{\mathrm{tm} 1 \mathrm{Bzh}}$ mice have robust ipsilateral CST misprojections (Paixao et al., 2013). Here, we injected anterograde tracer unilaterally into the motor cortex of Emx1-Cre; EphA $4{ }^{\text {tm2Kldr }}$ mice and followed the descending projection to the spinal cord. Figure 4 shows representative examples of descending cortical projections in WT (Fig. $4 A, C, E$ ) and Emx1-Cre; EphA $4^{\text {tm2Kldr }}$ (Fig. $4 B, D, F$ ) mice. As expected, unilateral motor cortex tracer injections in the Emx1-Cre;EphA4 ${ }^{\mathrm{tm} 2 \mathrm{Kldr}}$ mice labeled axons in the ipsilateral pyramid (Fig. $4 B$ ), a predominantly contralateral projection to the red nucleus (data not shown), and a bilateral projection to the pontomedullary reticular formation (Fig. $4 B$, white arrows mark labeled axons bilaterally into the ventral medulla). This is similar to the WT mice (Fig. $4 A$ ), which suggests that the loss of EphA4 in the descending cortical projection did not affect the laterality of the corticobulbar projections. Robust ipsilateral spinal terminations can be seen in the mutant (Fig. 4D), but not the wild-type mouse (Fig. 4C). The CST ipsilateral misprojection is due to axonal recrossing in the spinal cord, because the descending cortical projection from one hemisphere is restricted to the medullary pyramid on the same side 
A Over ground

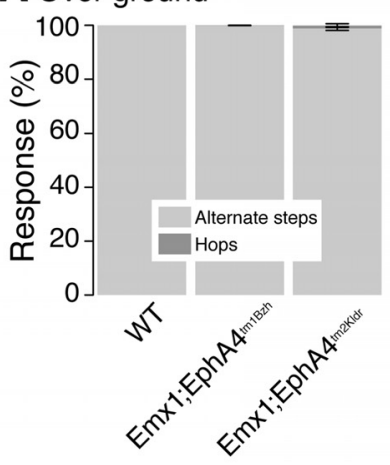

\section{Obstructed} $\left(\mathrm{Em} \times 1 ; \mathrm{EphA4} 4^{\mathrm{tm} 182 h}\right)$

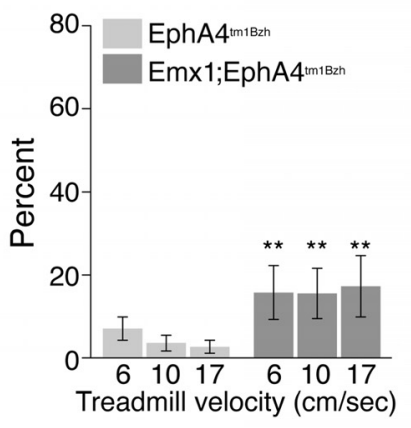

Exploratory reaching

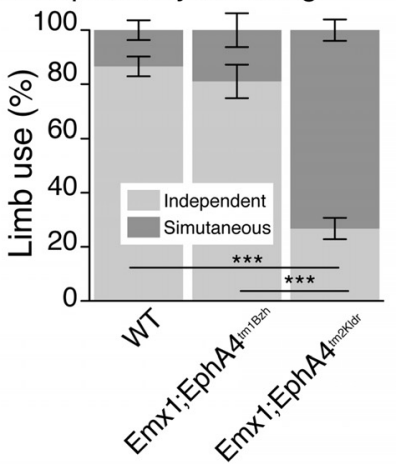

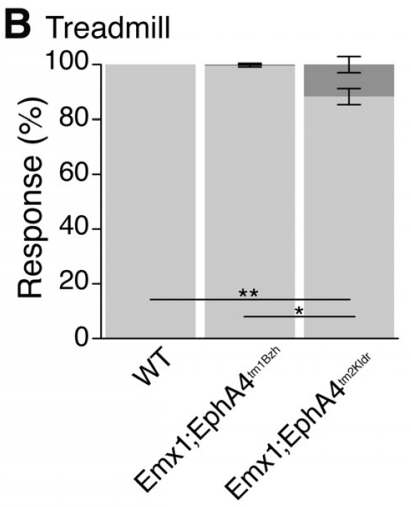

D Obstructed

(Emx1;EphA4 $4^{\text {tmekldr) }}$

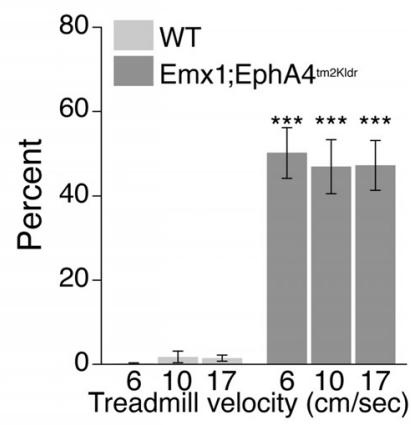

A

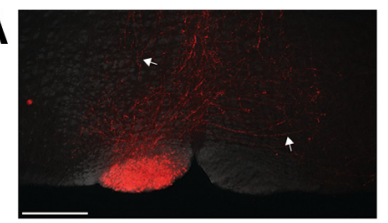

C

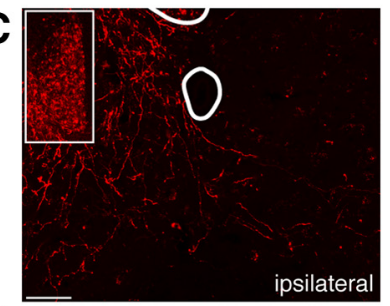

$\mathbf{E}$

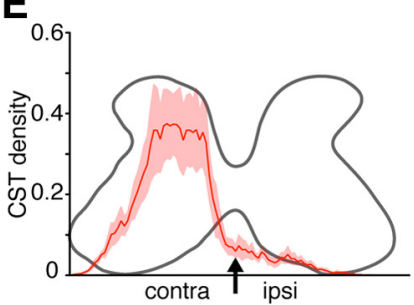

B

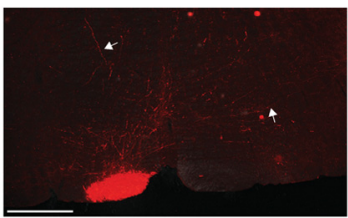

D

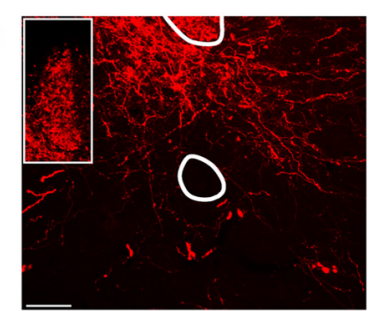

$\mathbf{F}$

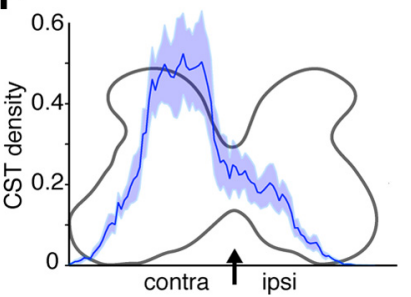

Figure 4. Bilateral CST terminations into cervical spinal cord in Emx1-Cre;EphA4 ${ }^{\mathrm{tm} 2 \mathrm{KIdr}}$ conditional mutant mice. $\boldsymbol{A}, \boldsymbol{B}, \mathrm{BDA}$-labeled axons in the medullary pyramid of WT $(\boldsymbol{A})$ and Emx1Cre;EphA4 ${ }^{\text {tm2KIdr }}(\boldsymbol{B})$ mice (calibration, $500 \mu \mathrm{m}$ ). Arrows point to corticoreticular projections to the ipsilateral and contralateral reticular formation in both mice (WT and Emx1-Cre; EphA4 $\left.{ }^{\mathrm{tm} 2 \mathrm{KIdr}}\right) . \boldsymbol{C}, \boldsymbol{D}$, Confocal images of BDA-labeled axons in the cervical enlargement $(C \mathrm{C} / \mathrm{C} 8)$ after unilateral injections of anterograde tracer BDA into the M1 (C, WT; D, Emx1-Cre; EphA4 $\left.{ }^{\mathrm{tm} 2 \mathrm{KIdr}}\right)$. Each image is a $z$-stack of 13 images (1 $\mu \mathrm{m}$ optical slices; calibration $\left.50 \mu \mathrm{m}\right)$. Note the extensive ipsilateral CST terminations in the Emx1-Cre;EphA4 ${ }^{\mathrm{tm} 2 \mathrm{Kldr}}$ mouse (D) and very sparse ipsilateral CST terminations in WT (C). The insets in $\boldsymbol{C}$ and $\boldsymbol{D}$ show similar CST labeling in the ventral dorsal column of each mouse. $\boldsymbol{E}, \boldsymbol{F}$, Mediolateral distributions of mean axon density from the left to the right borders of the contralateral and ipsilateral gray matter in the WT $(\boldsymbol{E})$ and Emx1-Cre;EphA4 ${ }^{\text {tm2KIdr }}$ mice $(\boldsymbol{F})$. Each graph plots the average CST density of axon terminations in Emx1-Cre;EphA4 ${ }^{\text {tm2Kldr }}(\boldsymbol{F})$ and WT mice $(\boldsymbol{E})$; light-shading plots \pm SEM. The arrows indicate the midline. There was a significant difference in the amount of ipsilateral, but not contralateral, labeling in the two groups (Mann-Whitney test, ipsilateral, $p=0.016$; contralateral, $p=0.31$ ).

and we did not note more ipsilateral descending CST projections in the white matter (data not shown).

We quantified CST labeling, correcting for tracer efficiency in

Figure 3. Effects of conditional elimination of EphA4 in the forebrain on forelimb movements during locomotion and exploratory reaching. $A, B$, Stacked histograms of forelimb locomotor behavior. During overground locomotion $(A)$, both mutant mice $(n=6-10)$ and WT mice $(n=10)$ step with their forelimbs nearly $100 \%$ of the time $(p=0.30, F=1.27$, one-way ANOVA, Bonferroni's posttest $p>0.05)$. During unobstructed treadmill locomotion (B), Emx1Cre;EphA4 ${ }^{\text {tm2KIdr }}$ mice $(n=15)$ only showed a slight but significant percentage of hopping compared with WT $(n=10)$ and Emx1-Cre;EphA4 ${ }^{\text {tm1Bzh }}$ mice ( $n=6$; one-way ANOVA, $p=$ $0.003, F=7.4$; Bonferroni's posttest $p<0.05$ ). $C, D$, Mean percent ( \pm SE) forelimb hopping during adaptive locomotion. Data for three 3 treadmill speeds $(6 \mathrm{~cm} / \mathrm{s} ; 10 \mathrm{~cm} / \mathrm{s} ; 17 \mathrm{~cm} / \mathrm{s})$ and one obstacle height $(1.0 \mathrm{~cm})$ are plotted (EphA4 ${ }^{\text {tm1Bzh }}, n=18$; Emx1-Cre;EphA4 ${ }^{\text {tm1Bzh }}, n=$ 18; WT, $n=10 ;$ Emx1-Cre;EphA4 $\left.{ }^{\text {tm2KIdr }}, n=15\right)$. There was a significant increase in hopping between conditional mutant groups and their respective controls: Emx1-Cre; EphA4 ${ }^{\mathrm{tm} 1 \mathrm{Bzh}}, F=$ $8.8, p=0.004$, no differences between treadmill velocities $(F=0.08, p=0.092)$; Emx1-Cre; EphA4 ${ }^{\mathrm{tm} 2 \mathrm{Kld}}, F=117, p<0.0001$, no differences between treadmill velocities, $F=0.02, p=$ 0.098. In addition, the Emx1-Cre;EphA4 ${ }^{\mathrm{tm} 2 \mathrm{KIdr}}$ mice showed a significant increase in hopping over EphA4 ${ }^{\text {tm2Kldr }}$ controls $\left(17 \mathrm{~cm} / \mathrm{s} ; 1 \mathrm{~cm}\right.$; forelimb: WT mean $=1.5 \% \pm 0.74 \%$; EphA4 ${ }^{\text {tm2Kldr }}$ mean $=2 \pm 2 \%$, Emx1-Cre;EphA4 ${ }^{\text {tm2KIdr. }}$ : mean $=47.2 \% \pm 5.9 \%, p<0.0001$, one-way ANOVA, Bonferroni's posttest revealed no difference between WT and EphA4 ${ }^{\mathrm{tm} 2 \mathrm{KId} r}, p>0.05$ ). $\boldsymbol{E}$, Histograms of forelimb reaching exploratory behavior. There was no statistically difference between WT and Emx1-Cre;EphA4 ${ }^{\mathrm{tm} 1 \mathrm{Bzh}}$ mice $(n=6 ; p>0.05)$. In contrast, Emx1-Cre; EphA4 ${ }^{\text {tm2KIdr }}$ mice $(n=10)$ showed a significant use of both forelimbs when reaching the wall of the cylinder compared with WT ( $n=11$; one-way ANOVA, $p<0.0001, F=66.9$; Bonferroni posttest, $p<0.05$ ). The schematic shows a diagram of a mouse in the reaching cylinder. each animal (see Materials and Methods), using two approaches. First, we plotted the total amount of CST labeling in the contralateral and ipsilateral gray matter from the lateral contralateral to the lateral ipsilateral gray matter border (Fig. $4 E, F$ ). Whereas there was a larger amount of contralateral CST labeling than in wild-type mice, suggestive of a role for EphA4 in axon refinement, comparison revealed no significant difference $(p=0.31)$. In contrast, there was a clear and significant $(p=0.016)$ difference in the amount of ipsilateral labeling. In the second approach, we determined the ratio of ipsilateral projections to the sum of contralateral plus ipsilateral projections, similar to what was done for Emx1-Cre;EphA4 ${ }^{\mathrm{tm} 1 \mathrm{Bzh}}$ mice (Paixao et al., 2013). Labeled CST axons were assayed within the entire gray matter on either side of the central canal (see Materials and Methods). There were significantly more ipsilateral CST axons in the gray matter of the Emx1-Cre;EphA4 ${ }^{\mathrm{tm} 2 \mathrm{Kldr}}$ than WT mice (ipsilaterality index for knock-out mice $=0.29 \pm 0.03$ and WT mice $=$ $0.12 \pm 0.02, p=0.008$, Mann-Whitney test, $n=5$ mice/group). The Emx1-Cre;EphA4 ${ }^{\text {tm2Kldr }}$ mice had 2.4 times more ipsilateral CST projections than WT mice. Therefore, conditional ablation 
of EphA4 in cortex resulted in robust aberrant ipsilateral CST projections.

\section{M1 motor-evoked effects parallel bilateral CST}

We next determined whether motor cortex stimulation in the Emx1-Cre;EphA4 ${ }^{\text {tm2Kldr }}$ mice is effective in evoking ipsilateral EMG responses. We have shown previously that motor cortex stimulation in Emx1-Cre;EphA4 ${ }^{\mathrm{tm} 1 \mathrm{Bzh}}$ mice evokes bilateral muscle responses (Paixao et al., 2013). Here, we used intracortical microstimulation (ICMS) to activate M1 motor circuits in Emx1Cre;EphA4 ${ }^{\text {tm2Kldr }}$ mice. We stimulated sites in M1 that produced forelimb flexion at threshold and evoked a contralateral biceps brachii muscle contraction at threshold and determined whether there was concurrent activation of the ipsilateral biceps muscle. Results in the Emx1-Cre;EphA4 ${ }^{\text {tm2Kldr }}$ mice were compared with controls (Emx1-Cre;EphA4 ${ }^{\text {tm2Kldr }}: n=5$ mice, 7 hemispheres, 26 stimulation sites; EphA4 ${ }^{\text {tm2Kldr }}: n=5$ mice, 7 hemispheres, $n=$ 27 sites). Ensemble averages of rectified EMG responses for the Emx1-Cre;EphA4 ${ }^{\mathrm{tm} 2 \mathrm{Kldr}}$ mice were strongly bilateral compared with contralateral responses in the EphA4 ${ }^{\text {tm2Kldr }}$ mice (Fig. $5 A-$ $D$ ). The amplitude of the ipsilateral response in the Emx1-Cre; EphA4 ${ }^{\text {tm2Kldr }}$ mice was, on average, comparable to that of the contralateral response. The mean laterality index for each group (integrated ipsilateral EMG value/integrated contralateral EMG value; Fig. $5 E$ ) was substantially and significantly higher in Emx1Cre;EphA4 ${ }^{\text {tm2Kldr }}$ than the control EphA4 ${ }^{\text {tm2Kldr }}$ mice. To compare Emx1-Cre;EphA4 ${ }^{\mathrm{tm} 2 \mathrm{Kldr}}$ and Emx1-Cre;EphA4 ${ }^{\mathrm{tm} 1 \mathrm{Bzh}}$ mice, we reanalyzed data from Paixao et al. (2013). The cumulative distributions of the laterality indices for the two mice are significantly different; the Emx1-Cre;EphA4 ${ }^{\text {tm } 2 \text { Kldr }}$ mice show a shift in the distribution to the right (Fig. 5F, solid arrow). These differences in ipsilateral response size were not accompanied by differences in response latency, determined by the lag time between the contralateral and ipsilateral responses at each stimulation site (ipsilateral latency - contralateral latency). This measure was between 1 and $2 \mathrm{~ms}$ and did not show any difference between groups, suggesting similarities in the underlying circuits (Emx1-Cre;EphA4 ${ }^{\text {tm2Kldr }}: 1.8 \mathrm{~ms} \pm 1.2 ;$ Emx1-Cre;EphA4 ${ }^{\text {tmlBzh }}$ : $1.9 \pm 1.4$; EphA4 ${ }^{\text {tm1Bzh }}: 1.1 \pm 1.4$; EphA4 ${ }^{\text {tm2Kldr }}: 1.6 \pm 1.1$; Kruskal-Wallis test, $p=0.97$, Dunn's posttest, $p>0.05$ ). These findings show that Emx1-Cre;EphA4 ${ }^{\mathrm{tm} 2 \mathrm{Kldr}}$ mice have strong connections with ipsilateral muscles (biceps brachii) and that these are stronger than what was previously reported for the Emx1-Cre;EphA4 ${ }^{\mathrm{tm} 1 \mathrm{Bzh}}$ mice.

\section{M1 mirror joint sites}

To further explore the stronger bilateral motor phenotype seen in the Emx1-Cre;EphA4 ${ }^{\text {tm2Kldr }}$ compared with the Emx1-Cre; EphA4 ${ }^{\mathrm{tm} 1 \mathrm{Bzh}}$ mice, we used ICMS to determine the cortical representation of bilateral forelimb movements at the same joint. We systematically stimulated 25 sites within the motor cortex, a region that comprised most of the caudal forelimb area and parts of the vibrissal and hindlimb areas. Stimulation of the vibrissal and hindlimb areas that adjoined the fore limb area served to define the boundaries of the forelimb region that we studied systematically. We identified those sites within the forelimb area where the ipsilateral and contralateral evoked forelimb responses were obtained at the same current threshold and the same forelimb movement at the same joint was evoked bilaterally. We termed these sites "mirror sites." Whereas nearly all sites in Emx1-Cre;EphA4 ${ }^{\text {tm2Kldr }}$ mice evoked mirror movements (color in plots shows the percentage of mirror sites at the stimulation site), Emx1-Cre;EphA4 ${ }^{\mathrm{tm} 1 \mathrm{Bzh}}$ mice showed more varied re-
A
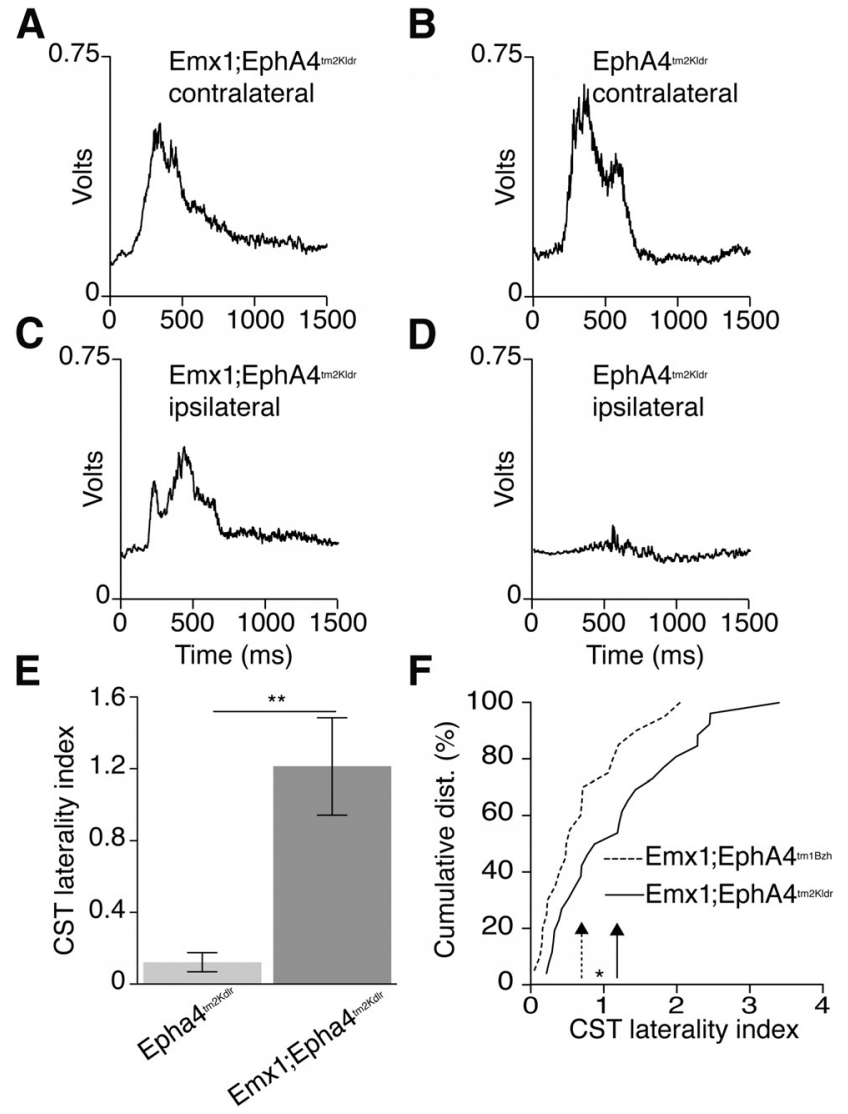

Figure 5. M1 stimulation-evoked bilateral forelimb response in EphA4 conditional mutant mice. $\boldsymbol{A}-\boldsymbol{D}$, Ensemble EMG averages from contralateral and ipsilateral biceps muscles in response to threshold cortical stimulation in Emx1-Cre; EphA4 ${ }^{\text {tm2Kldr }}(\boldsymbol{A}, \boldsymbol{C})$ and EphA4 ${ }^{\text {tm2KIdr }}$ controls $(\boldsymbol{B}, \boldsymbol{D})$. Each histogram plots the average of rectified EMG responses in each group. $\boldsymbol{E}$, Average laterality index (integrated ipsilateral EMG value divided by integrated contralateral EMG value) for each group. The EMG data show a robust bilateral motor response in Emx1-Cre; EphA4 ${ }^{\text {tm2Kldr }}$ and contralateral responses in the controls (Mann-Whitney test, $p=0.0012$ ). $\boldsymbol{F}$, Cumulative distribution of laterality index for each mutant mouse. The figure plots cumulative distribution functions of laterality indices across our sample of 26 recorded motor cortex sites in the Emx1-Cre;EphA4 ${ }^{\text {tm2Kldr }}$ (solid line) and 20 recorded sites in the Emx1-Cre;EphA4 ${ }^{\text {tm1Bzh }}$ mice (dashed line). The arrows indicate the distribution means, which are significantly different (Emx1-Cre;EphA4 ${ }^{\text {tm1Bzh }}:$ mean $=0.7 \pm 0.13$, Emx1-Cre;EphA4 ${ }^{\text {tm2KIdr. }}$ : mean $=1.2 \pm 0.17 ; t$ test, $p=0.032$; data reanalyzed from Paixão et al., 2013) and the distribution for the Emx1Cre;EphA4 ${ }^{\text {tm2Kldr }}$ mice is shifted to the right.

sponses (Fig. $6 A, B$ ). Emx1-Cre;EphA4 ${ }^{\text {tmlBzh }}$ mice had significantly fewer mirror sites than Emx1-Cre;EphA4 ${ }^{\text {tm2Kldr }}$ mice (Fig. $6 A-C)$. There were no mirror sites in the controls. Our findings demonstrate a strong bilateral representation of forelimb movement in motor cortex in the conditional knock-out mice. Furthermore, the Emx1-Cre;EphA4 ${ }^{\text {tm2Kldr }}$ mice have a significantly greater bilateral movement representation than Emx1-Cre; EphA4 ${ }^{\mathrm{tm} 1 \mathrm{Bzh}}$ mice, providing an explanation for why the Emx1Cre;EphA4 ${ }^{\text {tm2Kldr }}$ mice have a stronger bilateral voluntary motor phenotype.

\section{Discussion}

We studied cortical control of voluntary movement in mice with a selective and characteristic change in CST organization. By conditional forebrain ablation of the EphA4 gene, the CST is transformed from a motor system that is functionally and anatomically mainly contralateral to a bilateral system. With the mutation, motor control signals transmitted by the CST convert from predominantly contralateral to bilateral. Importantly, the 


\section{A Emx1;EphA4mimazh}

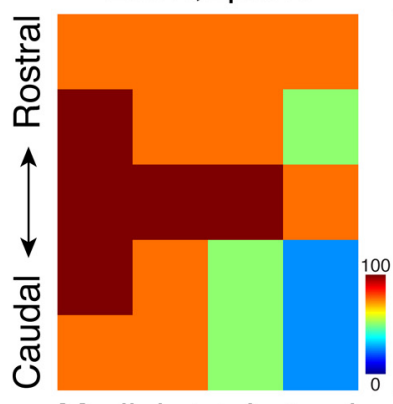

Medial $\leftrightarrow$ Lateral

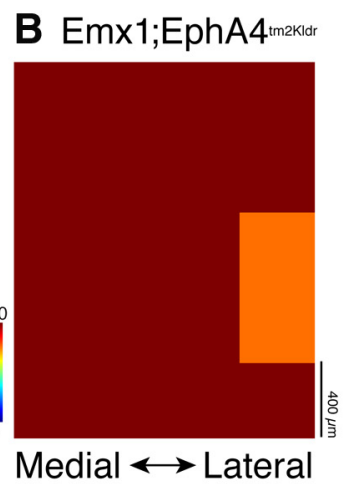

\section{C}

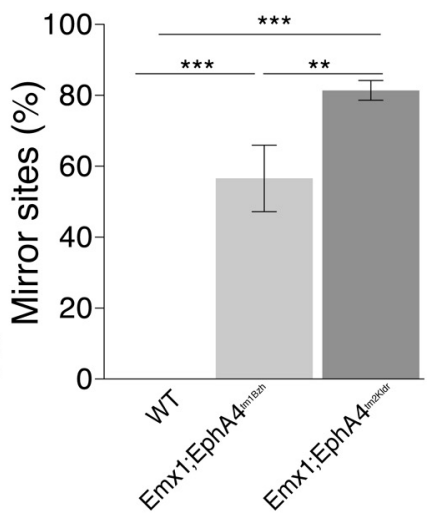

Figure 6. Mirror site representations at threshold in EphA4 conditional knock-out mice. Color maps plot the occurrence of evoked mirror movements at each of the motor cortex stimulation sites in Emx1-Cre;EphA4 ${ }^{\mathrm{tm} 1 \mathrm{Bzh}}(\boldsymbol{A})$ and Emx1-Cre; EphA4 ${ }^{\mathrm{tm} 2 \mathrm{KIdr}}$ mice $(\boldsymbol{B})$. The color represents a spectrum, from a high (maroon and red) to a low (blue) percentage of mirror sites. No mirror sites were found in the WT at the threshold. Whereas nearly all sites in Emx1-Cre;EphA4 ${ }^{\text {tm2KIdr }}$ mice evoked mirror movements, Emx1-Cre;EphA4 ${ }^{\mathrm{tm} 1 \mathrm{Bzh}}$ mice showed more varied responses. Bar graphs in C plot the average ( $n=4-5$ mice/group; $n=25$ motor cortex sites within each of 17 hemispheres) of the percentage of sites from which the microstimulation evoked a mirror response. There was a significantly higher percentage of mirror sites in Emx1-Cre;EphA4 ${ }^{\mathrm{tm} 2 \mathrm{Kld}}$ mice (dark gray bar) than in Emx1-Cre; EphA4 ${ }^{\mathrm{tm} 1 \text { Bzh }}$ mice (light gray bar; one-way ANOVA, $p<0.0001, F=94 ; p<0.05$, Bonferroni post hoc test).

terneurons in WT animals. If cortical EphA4 levels are regionally determined in motor cortex, as other Eph receptors and ephrins are involved in shaping visual system connections (McLaughlin and O'Leary, 2005), then proximal muscle representations with greater bilateral control functions could develop more bilateral spinal projections than distal muscle representations serving more individuated control. Targeting of CST axons to spinal interneurons serving proximal or distal control (Asante and Martin, 2013), both contralaterally and ipsilaterally, could be guided by differential expression of EphA4 ligands (e.g., EphrinB3) in interneurons, as shown for lateral motoneurons and their limb targets (Kania and Jessell, 2003).

\section{Cortical EphA4 ablation, bilateral voluntary movements, and the central motor representation}

During adaptive locomotion, there is a single-cycle modification of stepping and

genetic manipulation spares other motor systems, including spinal motor circuits that are known to be sensitive to EphA4 reduction. Our results show that when the ipsilateral CST is sufficiently strong, which is determined by the interplay between the ipsilateral CST misprojections and the bilateral cortical motor representation, a "bilateral signature" is imprinted upon voluntary movements, but not upon stereotypic locomotion.

\section{Determinants of the extent of ipsilateral CST misprojections}

The density of ipsilateral CST misprojections is key to the bilateral movement representation in the motor cortex and bilateral voluntary movements. Present and previous findings suggest that ipsilateral CST misprojections depend largely on lower EphA4 levels in motor cortex, which reduce forward signaling during development and thus augment spinal CST axon decussation (Dottori et al., 1998). Whereas there may be some postnatal elimination of ipsilateral CST terminations, a process shown to be activity dependent (Martin et al., 2009), a substantial number of ipsilateral spinal projections remains and this provides the substrate for the physiological and functional changes. Whereas we do not understand why there were lower EphA4 protein levels in the motor cortex of the Emx1-Cre;EphA $4{ }^{\text {tm2Kldr }}$ than the Emx1Cre;EphA $4^{\mathrm{tm} 1 \mathrm{Bzh}}$ mice, it suggests that there was a greater proportion of corticospinal neurons without EphA4 compared with neurons that still express EphA4. This would lead to a greater loss of EphA4 forward signaling in CST axons during development and a stronger bilateral voluntary motor phenotype in the Emx1Cre;EphA $4^{\mathrm{tm} 2 \mathrm{Kldr}}$ mice. The lack of changes in spinal EphA4 level, the laterality of spinal interneuron projections, the lack of overground hopping, and the similarity in latency and form of cortical evoked responses all point to no substantive change in segmental circuits due to the conditional EphA4 elimination in the Emx1-Cre;EphA4 ${ }^{\text {tm2Kldr }}$ mice. Nevertheless, we cannot rule out that a small subcortical reduction in EphA4 could contribute to the bilateral voluntary motor phenotype. The differential CST EphA4 levels not only help to inform the motor findings in the two knock-outs, but may also provide insight into the regulation of spinal CST axon crossing and connections with spinal in- elbow flexion is increased to raise the paw over the obstacle, without major changes in the trajectory or the pattern or timing of muscle activity (Drew, 1993; Lavoie et al., 1995; Friel et al., 2007; Asante et al., 2010). To step appropriately, the animal must coordinate its pace with treadmill speed and obstacle location and scale paw height with obstacle height. Navigating over the obstacle thus requires supraspinal control. This trajectory modification, which is guided by vision/vibrissal information, is accompanied by modulation of the activity of motor cortex and pyramidal tract neurons controlling elbow flexors (Drew et al., 2008). The first limb to step over the obstacle, termed the lead limb, is controlled by contralateral frontoparietal circuits (Lajoie et al., 2010). The trailing limb over the obstacle can be controlled redundantly by feedforward and/or leading limb feedback signals. We hypothesize that, after EphA4 elimination in cortex, contralateral control of the leading limb becomes bilateral (hop), thereby obviating subsequent trailing limb control.

With a further reduction in EphA4 in cortex in the Emx1-Cre; EphA $4^{\text {tm2Kldr }}$ mice, there is a higher incidence of hopping over the obstacle and increased mirror reaching compared with Emx1-Cre;EphA4 ${ }^{\mathrm{tm} 1 \mathrm{Bzh}}$ mice. Differences in behavioral constraints and spinal circuit features for the two tasks help establish a lower threshold for evoking bilateral CST control of adaptive locomotion than reaching. Adaptive locomotion may be more vulnerable to bilateral CST control than reaching, because the two forelimbs normally are bilaterally coordinated during locomotion, albeit with an alternating phase dependence (Kiehn, 2006). Further, adaptive locomotion likely recruits spinal CPG circuits that normally have bilateral connections; for example, spinal commissural interneurons (Kiehn and Butt, 2003) and spinal partition and midline cholinergic cells (Zagoraiou et al., 2009; Enjin et al., 2010; Huang et al., 2000), which receive direct CST contacts (Chakrabarty et al., 2009) and have a bilateral subpopulation (Stepien et al., 2010). CST engagement of either of these neurons may confer a strong vulnerability to bilaterally yoked movements in both conditional knock-outs. In contrast, the threshold for evoking bilateral reaching is much higher. Forelimb use during reaching normally is strongly independent. In 
humans, despite the presence of a ipsilateral CST projections to the cervical spinal cord (Schoen, 1964), mirror movements are not normally expressed in maturity. Mirror movements are observed in humans (and animals) when there are strong, reactive ipsilateral projections from the undamaged side, after unilateral motor cortex/CST damage (Woods and Teuber, 1978; Tsuboi et al., 2010). Mirror movements and bilateral motor unit synchrony are also observed in several genetic conditions in humans with very strong bilateral CST spinal projections (Farmer et al., 1990; Mayston et al., 1997).

For cats and monkeys, targeted reaching in the context of food-taking recruits unilateral propriospinal and segmental networks (Alstermark and Isa, 2012) that may have a minimal involvement in stereotypic locomotion (Alstermark and Kümmel, 1990). A homologous class of propriospinal neuron receiving CST input has not been identified in the mouse (Alstermark and Ogawa, 2004). Because the laterality of the rubrospinal and reticulospinal systems, both of which are engaged in adaptive locomotion and reaching (Rho et al., 1999; Matsuyama et al., 2004), remains unchanged, the incidence of aberrant bilateral voluntary movement may scale inversely with cortical EphA4 levels.

Substantial loss of EphA4 in motor cortex resulted in establishment of a bilateral motor representation. With lower EphA4 levels comes a stronger bilateral voluntary motor cortex phenotype, which includes substantially larger ipsilateral biceps EMG responses. Comparison of the present data with our recent findings (Paixao et al., 2013) shows that the structure of the contralateral and ipsilateral muscle responses (latency and form) evoked by motor cortex stimulation in the two conditional knock-out mice are identical. This suggests that the initial muscle response evoked by motor cortex stimulation is driven by activation of a strongly bilateral CST that contacts predominantly ipsilateralprojecting spinal interneurons. This similarity in the structure of the evoked response further suggests that the spinal circuits transducing cortical signals are not substantially different from WT mice.

\section{Bilateral CST without bilateral stereotypic locomotion}

Hopping in the conditional EphA4 knock-outs is associated with adaptive, not stereotypic, overground locomotion, whereas hopping in EphA4 null mutants is consistently present during overground locomotion (Akay et al., 2006). Hopping occurs during both stereotypic and adaptive locomotion over obstacles in $\alpha$-2Chimaerin full knock-outs (Beg et al., 2007; Asante et al., 2010). Our present findings suggest that hopping during overground locomotion in the null mutants depends on spinal interneuron, not CST bilateral, miswiring. This is consistent both with the substantial increase in aberrant ipsilateral projections of spinal interneurons (Butt et al., 2005) and in vitro demonstration of synchronous motor output without cerebral input (Kullander et al., 2003). Retrograde labeling of spinal interneurons in the adult Emx1-Cre;EphA4 ${ }^{\text {tm2Kldr }}$ mouse did not reveal ipsilateral interneuron misprojections, further supporting selective CST involvement.

The role of motor cortex and the CST in stereotypic locomotion is not well understood. Motor cortex neurons, even pyramidal tract neurons, modulate their activity during stereotypic locomotion (Beloozerova et al., 2003; Drew et al., 2004) and it is not known whether this activity is driven by limb afferent feedback or feedforward descending control. Conversely, inactivation and lesion of motor cortex/CST has a minimal effect on stereotypic locomotion (Beloozerova and Sirota, 1993; Asante et al., 2010). Importantly, neither knock-out mouse displayed hop- ping during overground locomotion, when CPGs are recruited. Hopping over the obstacle in the EphA4 conditional knock-outs is not determined by engagement of locomotor CPG circuits, but by the presence of the obstacle. Selective hopping during adaptive locomotion further stresses that the motor cortex and CST do not exert substantive moment-to-moment regulation of the trajectory and pace of stereotypic locomotion. This does not mean that the corticospinal system is not engaged during stereotypic locomotion. The fact that the motor cortex is capable of resetting the CPG during locomotion by curtailing stance and promoting swing (Rho et al., 1999) and that its activity modulates with locomotor accuracy demands (Stout and Beloozerova, 2013) suggest that it is poised to adaptively modify stereotypic locomotion in response to task constraints.

\section{References}

Akay T, Acharya HJ, Fouad K, Pearson KG (2006) Behavioral and electromyographic characterization of mice lacking EphA4 receptors. J Neurophysiol 96:642-651. CrossRef Medline

Alstermark B, Isa T (2012) Circuits for skilled reaching and grasping. Annu Rev Neurosci 35:559-578. CrossRef Medline

Alstermark B, Kümmel H (1990) Transneuronal transport of wheat germ agglutinin conjugated horseradish peroxidase into last order spinal interneurones projecting to acromio- and spinodeltoideus motoneurones in the cat. 2. Differential labelling of interneurones depending on movement type. Exp Brain Res 80:96-103. Medline

Alstermark B, Ogawa J (2004) In vivo recordings of bulbospinal excitation in adult mouse forelimb motoneurons. J Neurophysiol 92:1958-1962. CrossRef Medline

Asante CO, Martin JH (2013) Motor cortex co-represents forelimb joints and differential corticospinal access to spinal segmental regions and interneuron populations in the mouse. PLoS One 8:e74454. CrossRef Medline

Asante CO, Chu A, Fisher M, Benson L, Beg A, Scheiffele P, Martin J (2010) Cortical control of adaptive locomotion in wild-type mice and mutant mice lacking the Ephrin-Eph effector protein \{alpha\}2-chimaerin. J Neurophysiol 104:3189-3202. CrossRef Medline

Beg AA, Sommer JE, Martin JH, Scheiffele P (2007) alpha2-Chimaerin is an essential EphA4 effector in the assembly of neuronal locomotor circuits. Neuron 55:768-778. CrossRef Medline

Beloozerova IN, Sirota MG (1993) The role of the motor cortex in the control of vigour of locomotor movements in the cat. J Physiol 461:27-46. Medline

Beloozerova IN, Sirota MG, Swadlow HA (2003) Activity of different classes of neurons of the motor cortex during locomotion. J Neurosci 23:10871097. Medline

Butt SJ, Lundfald L, Kiehn O (2005) EphA4 defines a class of excitatory locomotor-related interneurons. Proc Natl Acad Sci U S A 102:1409814103. CrossRef Medline

Chakrabarty S, Shulman B, Martin JH (2009) Activity-dependent codevelopment of the corticospinal system and target interneurons in the cervical spinal cord. J Neurosci 29:8816-8827. CrossRef Medline

Coonan JR, Greferath U, Messenger J, Hartley L, Murphy M, Boyd AW, Dottori M, Galea MP, Bartlett PF (2001) Development and reorganization of corticospinal projections in EphA4 deficient mice. J Comp Neurol 436:248-262. Medline

Dottori M, Hartley L, Galea M, Paxinos G, Polizzotto M, Kilpatrick T, Bartlett PF, Murphy M, Köntgen F, Boyd AW (1998) EphA4 (Sek1) receptor tyrosine kinase is required for the development of the corticospinal tract. Proc Natl Acad Sci U S A 95:13248-13253. CrossRef Medline

Drew T (1993) Motor cortical activity during voluntary gait modifications in the cat. I. Cells related to the forelimbs. J Neurophysiol 70:179-199. Medline

Drew T, Prentice S, Schepens B (2004) Cortical and brainstem control of locomotion. Prog Brain Res 143:251-261. CrossRef Medline

Drew T, Andujar JE, Lajoie K, Yakovenko S (2008) Cortical mechanisms involved in visuomotor coordination during precision walking. Brain Res Rev 57:199-211. CrossRef Medline

Enjin A, Rabe N, Nakanishi ST, Vallstedt A, Gezelius H, Memic F, Lind M, Hjalt T, Tourtellotte WG, Bruder C, Eichele G, Whelan PJ, Kullander K 
(2010) Identification of novel spinal cholinergic genetic subtypes disclose Chodl and Pitx2 as markers for fast motor neurons and partition cells. J Comp Neurol 518:2284-2304. CrossRef Medline

Farmer SF, Ingram DA, Stephens JA (1990) Mirror movements studied in a patient with Klippel-Feil syndrome. J Physiol 428:467-484. Medline

Filosa A, Paixao S, Honsek SD, Carmona MA, Becker L, Feddersen B, Gaitanos L, Rudhard Y, Schoepfer R, Klopstock T, Kullander K, Rose CR, Pasquale EB, Klein R (2009) Neuron-glia communication via EphA4/ ephrin-A3 modulates LTP through glial glutamate transport. Nat Neurosci 12:1285-1292. CrossRef Medline

Friel KM, Drew T, Martin JH (2007) Differential activity-dependent development of corticospinal control of movement and final limb position during visually-guided locomotion. J Neurophysiol 97:3396-3406. CrossRef Medline

Friel K, Chakrabarty S, Kuo HC, Martin J (2012) Using motor behavior during an early critical period to restore skilled limb movement after damage to the corticospinal system during development. J Neurosci 32: 9265-9276. CrossRef Medline

Galley S, Clowry GJ (2010) Plasticity to neonatal sensorimotor cortex injury. Translational Neuroscience 1:16-23. CrossRef

Ghez C, Hening W, Gordon J (1991) Organization of voluntary movement. Curr Opin Neurobiol 1:664-671. CrossRef Medline

Gorski JA, Talley T, Qiu M, Puelles L, Rubenstein JL, Jones KR (2002) Cortical excitatory neurons and glia, but not GABAergic neurons, are produced in the Emx1-expressing lineage. J Neurosci 22:6309-6314. Medline

Herrmann JE, Pence MA, Shapera EA, Shah RR, Geoffroy CG, Zheng B (2010) Generation of an EphA4 conditional allele in mice. Genesis 48: 101-105. CrossRef Medline

Huang A, Noga BR, Carr PA, Fedirchuk B, Jordan LM (2000) Spinal cholinergic neurons activated during locomotion: localization and electrophysiological characterization. J Neurophysiol 83:3537-3547. Medline

Iwasato T, Katoh H, Nishimaru H, Ishikawa Y, Inoue H, Saito YM, Ando R, Iwama M, Takahashi R, Negishi M, Itohara S (2007) Rac-GAP alphachimerin regulates motor-circuit formation as a key mediator of EphrinB3/EphA4 forward signaling. Cell 130:742-753. CrossRef Medline

Kania A, Jessell TM (2003) Topographic motor projections in the limb imposed by LIM homeodomain protein regulation of ephrin-A:EphA interactions. Neuron 38:581-596. CrossRef Medline

Kiehn O (2006) Locomotor circuits in the mammalian spinal cord. Annu Rev Neurosci 29:279-306. CrossRef Medline

Kiehn O, ButtSJ (2003) Physiological, anatomical and geneticidentification of CPG neurons in the developing mammalian spinal cord. Prog Neurobiol 70:347-361. CrossRef Medline

Kullander K, Mather NK, Diella F, Dottori M, Boyd AW, Klein R (2001a) Kinase-dependent and kinase-independent functions of EphA4 receptors in major axon tract formation in vivo. Neuron 29:73-84. CrossRef Medline

Kullander K, Croll SD, Zimmer M, Pan L, McClain J, Hughes V, Zabski S, DeChiara TM, Klein R, Yancopoulos GD, Gale NW (2001b) Ephrin-B3 is the midline barrier that prevents corticospinal tract axons from recrossing, allowing for unilateral motor control. Genes Dev 15:877-888. CrossRef Medline

Kullander K, Butt SJ, Lebret JM, Lundfald L, Restrepo CE, Rydström A, Klein R, Kiehn O (2003) Role of EphA4 and EphrinB3 in local neuronal circuits that control walking. Science 299:1889-1892. CrossRef Medline

Lajoie K, Andujar JE, Pearson K, Drew T (2010) Neurons in area 5 of the posterior parietal cortex in the cat contribute to interlimb coordination during visually guided locomotion: a role in working memory. J Neurophysiol 103:2234-2254. CrossRef Medline

Lavoie S, McFadyen B, Drew T (1995) A kinematic and kinetic analysis of locomotion during voluntary gait modification in the cat. Exp Brain Res 106:39-56. CrossRef Medline

Martin J, Friel K, Salimi I, Chakrabarty S (2009) Corticospinal development. In: Encyclopedia of neuroscience (Squire L, ed), pp 302-214. Oxford: Academic.

Matsuyama K, Mori F, Nakajima K, Drew T, Aoki M, Mori S (2004) Locomotor role of the corticoreticular-reticulospinal-spinal interneuronal system. Prog Brain Res 143:239-249. CrossRef Medline

Mayston MJ, Harrison LM, Quinton R, Stephens JA, Krams M, Bouloux PM (1997) Mirror movements in X-linked Kallmann's syndrome. I. A neurophysiological study. Brain 120:1199-1216. CrossRef Medline

McLaughlin T, O'Leary DD (2005) Molecular gradients and development of retinotopic maps. Annu Rev Neurosci 28:327-355. CrossRef Medline

Paixão S, Balijepalli A, Serradj N, Niu J, Luo W, Martin JH, Klein R (2013) EphrinB3/EphA4-mediated guidance of ascending and descending spinal tracts. Neuron 80:1407-1420. CrossRef Medline

Rho MJ, Lavoie S, Drew T (1999) Effects of red nucleus microstimulation on the locomotor pattern and timing in the intact cat: a comparison with the motor cortex. J Neurophysiol 81:2297-2315. Medline

Schallert T, Fleming SM, Leasure JL, Tillerson JL, Bland ST (2000) CNS plasticity and assessment of forelimb sensorimotor outcome in unilateral rat models of stroke, cortical ablation, parkinsonism and spinal cord injury. Neuropharmacology 39:777-787. CrossRef Medline

Schoen J (1964) Comparative aspects of the descending fiber systems in the spinal cord. Prog Brain Res 11:203-222. CrossRef Medline

Starkey ML, Barritt AW, Yip PK, Davies M, Hamers FP, McMahon SB, Bradbury EJ (2005) Assessing behavioural function following a pyramidotomy lesion of the corticospinal tract in adult mice. Exp Neurol 195:524-539. CrossRef Medline

Stepien AE, Tripodi M, Arber S (2010) Monosynaptic rabies virus reveals premotor network organization and synaptic specificity of cholinergic partition cells. Neuron 68:456-472. CrossRef Medline

Stout EE, Beloozerova IN (2013) Differential responses of fast- and slowconducting pyramidal tract neurons to changes in accuracy demands during locomotion. J Physiol 591:2647-2666. CrossRef Medline

Tan AM, Chakrabarty S, Kimura H, Martin JH (2012) Selective corticospinal tract injury in the rat induces primary afferent fiber sprouting in the spinal cord and hyperreflexia. J Neurosci 32:12896-12908. CrossRef Medline

Tsuboi F, Nishimura Y, Yoshino-Saito K, Isa T (2010) Neuronal mechanism of mirror movements caused by dysfunction of the motor cortex. Eur J Neurosci 32:1397-1406. CrossRef Medline

Wegmeyer H, Egea J, Rabe N, Gezelius H, Filosa A, Enjin A, Varoqueaux F, Deininger K, Schnütgen F, Brose N, Klein R, Kullander K, Betz A (2007) EphA4-Dependent Axon Guidance Is Mediated by the RacGAP alpha2Chimaerin. Neuron 55:756-767. CrossRef Medline

Woods BT, Teuber HL (1978) Mirror movements after childhood hemiparesis. Neurology 28:1152-1157. CrossRef Medline

Yokoyama N, Romero MI, Cowan CA, Galvan P, Helmbacher F, Charnay P, Parada LF, Henkemeyer M (2001) Forward signaling mediated by ephrin-B3 prevents contralateral corticospinal axons from recrossing the spinal cord midline. Neuron 29:85-97. CrossRef Medline

Zagoraiou L, Akay T, Martin JF, Brownstone RM, Jessell TM, Miles GB (2009) A cluster of cholinergic premotor interneurons modulates mouse locomotor activity. Neuron 64:645-662. CrossRef Medline 